\title{
DO CAIS À CIDADE E DA CIDADE AO CAIS, AS REVITALIZAÇÕES DAS FRENTES D’ÁGUA E O RESGATE DA MEMÓRIA NA CIDADE-PORTO
}

\author{
Perla Duarte do Couto ${ }^{1}$ \\ Tânia Marques Strohaecker²
}

\begin{abstract}
Resumo: Este artigo propõe trazer ao debate, a partir da teoria e revisão bibliográfica, as implicações promovidas pelos processos das revitalizações portuárias nas cidades que possuem suas antigas áreas em ruínas, desativadas e/ou subutilizadas. Atualmente, encontramse em voga os processos de retomada destes espaços e que, por sua vez, representam expoente potencial dos usos, seja para o lazer, bem como para desenvolvimento econômico, como no caso da atividade turística. Nesse contexto, as áreas portuárias e os centros históricos são alvo das políticas urbanas que, acima de tudo, enfatizam a cultura, a história e a memória da formação urbana, enquanto patrimônio. Metodologicamente, este trabalho analisa a relação entre processos, funções e formas refletidas nas estruturas urbanas contemporâneas e nos processos de ascensão e declínio a partir dos usos de fragmentos dos espaços urbanos.
\end{abstract}

Palavras-chave: Revitalização urbana. Frente de água. Memória da cidade.

\section{FROM THE WHARF TO THE CITY AND TO THE CITY TO THE WHARF, THE REVITALIZATIONS OF THE WATERFRONT AND THE RESCUE OF THE MEMORY IN THE CITY-PORT}

\begin{abstract}
This article proposes to bring to discussion, from the theory and bibliographical revision, the implications promoted by the processes of port revitalization in the cities that have their old ruined areas, deactivated and / or underutilized. Nowadays, the processes of retaking these spaces are popular and, in addiction, represent a potential exponent of uses, whether for leisure or economic development, as tourism. In this conditions, the wharf areas and historical centers are the target of urban policies, that mainly emphasizes culture, history and the memory of urban formation as amenities. Therefore, this article brings to analyze the processes, functions, and forms reflected in contemporary urban structures and in the processes of rise and decline, from the uses of urban spaces fragments.
\end{abstract}

Keywords: Urban revitalization. Waterfront. Memory city.

\section{DEL CALES LA CIUDAD Y LA CIUDAD AL CALES, LAS REVITALIZACIONES DE LAS FRENTES DE AGUA Y EL RESCATE DE LA MEMORIA EN LA CIUDAD- PUERTO}

Resumen: Este artículo propone traer al debate, a partir de la teoría y revisión bibliográfica, las implicaciones promovidas por los procesos de las revitalizaciones portuarias en las ciudades que poseen sus antiguas áreas en ruinas, deshabilitadas y / o infrautilizadas. Actualmente, se encuentran en boga los procesos de retomada de estos espacios y que, a su vez, representan exponente potencial de usos, sea para el ocio, así como para el desarrollo económico, como en el caso de la actividad turística. En este contexto, las áreas portuarias y

\footnotetext{
1 Doutoranda em Geografia pela Universidade Federal do Rio Grande do Sul UFRGS. Email: perlacouto@gmail.com

${ }^{2}$ Universidade Federal do Rio Grande do Sul - UFRGS. Programa de Pós Graduação em Geografia/POSGea. Email: taniastro@gmail.com
} 
los centros históricos son objeto de las políticas urbanas, que por encima de todo enfatizan la cultura, la historia y la memoria de la formación urbana como amenidades. Para tanto este artículo trae al análisis frente a los procesos, formas y funciones reflejadas en las estructuras urbanas contemporáneas.

Palabras clave: Revitalización urbana. Frente al agua. Memoria de la ciudad

\section{Introdução}

A maioria das cidades portuárias tem a sua origem no porto e, assim, o cais representa um "embrião" do surgimento do núcleo urbano. Diante disso, as cidades que abrigam os portos desde a sua origem, os portos primitivos, tiveram como base as atividades portuárias que contribuíram para o seu desenvolvimento econômico e social. Assim, o espaço urbano é aqui compreendido como produto espacial e resultante das forças entre os agentes promotores do espaço em diferentes temporalidades.

Dessa forma, os distintos espaço-tempos são apresentados na paisagem urbana pelos aspectos materiais e imateriais, os quais se distinguem neste estudo por meio das noções entre as dimensões funcionais e simbólicas. Portanto, sobre a lógica de valorização/desvalorização em diferentes espaço-tempos é que consiste a metodologia de análise espacial de parcelas do espaço urbano, nesse caso, as áreas em obsolescência. Sobre o enfoque nas áreas portuárias em desuso ou subutilizadas, se consolida a metodologia de análise das relações entre processos, funções e formas, que podem ser constatadas por meio da estrutura urbana alterada a partir dos usos (funções), bem como valorizações em tempos e espaços distintos. Nesse sentido, Corrêa (1995: 28, 29) esclarece:

a) Forma é o aspecto visível, exterior de um objeto, referindo-se ainda ao arranjo espacial de um conjunto de objetos, que passa a se constituir em um padrão espacial;

b) A função implica uma tarefa, atividade ou papel a ser desempenhado pelo objeto criado;

c) Estrutura é relativa ao modo como os objetos estão organizados, refere-se não a um padrão espacial, mas a maneira como estão inter-relacionados entre si;

d) O processo é definido como uma ação que se realiza continuamente, objetivando algum resultado, implicando tempo e mudança. 
Nessa perspectiva, partimos da análise de que as dimensões supracitadas são orquestradas, no caso das revitalizações, de um lado, pelas forças do Estado e, do outro, pela iniciativa privada. Assim, a apropriação dos espaços públicos ${ }^{3}$ pela sociedade civil, a partir do cotidiano, por meio dos usos e pela práxis, podem garantir a permanência e as funções que integram a coletividade, seja para geração de renda dos diversos estratos sociais ou pelo acesso à circulação, cultura e lazer, entre outros exemplos. As relações público/privado que são, por vezes, antagônicas e outras convergentes, expressam as contradições conflitantes e inerentes à produção, bem como estão presentes de forma significativa nas análises sobre as áreas de revitalizações urbanas. No entanto, da relação entre políticas públicas, gestão do Estado em conjunto com os investimentos da iniciativa privada surgem as operações urbanas consorciadas e com elas as implicações na estrutura da cidade. Essa simbiose pode resultar nas diferenciações de áreas e nos processos de segregação espacial.

Nesse sentido, na perspectiva geográfica da produção do espaço urbano, pode-se constatar que as áreas alvo das intervenções podem conter o processo dinâmico e espacial da segregação (CORRÊA, 1989). Vale salientar que permanece a forma com a mudança de conteúdo (social e dos usos). Por isso, o conteúdo varia de acordo com a função atribuída à forma. Assim, ao passo que os projetos de retomada destes espaços são consolidados, seja no médio ou longo prazos, o processo de inércia, que preserva aspectos do passado, ou seja, a memória urbana (ABREU, 2012), pode ser exaltada ou sucumbir.

Para elaboração deste artigo, a metodologia consistiu na revisão de estudos realizados sobre o tema das revitalizações por autores especializados, tais como: Couto (2014), Galimbert (2014), Vasques (2006), Sànchez (2010), Hoyle (1994), Serpa (2007), BidouZachariasen (2006), Da Costa (2009), em destaque para as frentes d'água. Aliado ao tema das revitalizações, ao abordar questões pertinentes à escala do local, das relações entre o simbólico e a função urbana, e a memória urbana, Abreu (1998) e Halbwachs (1990) trazem importantes contribuições. Diante do contexto em voga, este estudo traz ao debate as relações entre as intervenções nas frentes d'água e a memória da cidade. Ao considerar as diversas relações nas formações sócioespaciais e bases teóricas em Lefebvre (1991) na articulação

\footnotetext{
${ }^{3}$ Público aqui entendido como local do encontro, de relações sociais. O espaço público é aquele de uso comum e posse de todos. Nestes locais, desenvolvemos atividades coletivas, como o convívio de diversos grupos que chamamos de sociedade urbana. Existem (pelo menos) dois tipos de espaços públicos: os espaços públicos livres (em que é pleno o direito de ir e vir) definidos de circulação (ruas e avenidas), e os espaços de lazer e conservação (praças, praias e parques). Mesmo admitindo-se que o Estado, como agente produtor do espaço, se posicione, muitas vezes, como uma empresa.
} 
entre as escalas, bem como na dinâmica espacial em Corrêa (1989), as dimensões (simbólica - funcional) contribuem para o entendimento das relações espaço-tempo sob a égide da economia e valorização/desvalorização do espaço urbano que, na contemporaneidade, ocasionam as revitalizações. Vale salientar que o estudo em questão enfatiza as análises nas áreas portuárias. Além disso, a revisão dos conceitos para o esclarecimento entre a metodologia e a operacionalização sobre renovação, reabilitação, requalificação urbana e a revitalização. Para tanto, encontramos subsídios substanciais na Carta de Lisboa (1995), Moura (1995), Guerra (1996), que versam sobre os conceitos, bem como realizam o aprofundamento acerca das implicações desses processos sobre o planejamento e gestão urbana.

O artigo é composto pela introdução seguida do item I, com breve apresentação sobre os conceitos que contém as diferentes faces das intervenções urbanas, mas que apresentam conteúdos espaciais semelhantes de apropriação e valorização dos espaços urbanos em obsolescência. Os conceitos levam a uma leitura ampla sobre os processos apresentados aqui em escala global, de uma ordem distante. Posteriormente, segue o tópico que versa a respeito das relações entre as revitalizações e as frentes d'água que, por suposto, apresentam diferenciais sobre outras cidades que não possuíram atividades portuárias. Assim, trazemos as relações de proximidades, na escala intraurbana do cotidiano e da produção espacial pela práxis, em consonância com a escala global de valorização dos espaços, que são evocados pelas ordens distantes e próximas. $\mathrm{O}$ item 3 remete às cidades portuárias relacionadas com a memória urbana a partir das revitalizações urbanas, promovendo a articulação entre as dimensões funcionais e simbólicas. Nesse sentido, o item 3 reforça a ideia de que a memória coletiva, a memória da cidade se desenvolva em um quadro espacial e, por conseguinte, na escala local. Por isso, as revitalizações devem - ou deveriam - considerar a história e a memória das cidades, ou seja, das localidades beneficiadas, bem como considerar as diversidades sociais. Por fim, o tópico 4 apresenta as considerações finais a respeito das relações entre a produção do espaço urbano e as revitalizações nas cidades portuárias quanto à história e memória urbanas.

\section{Breve discussão sobre o conceito de revitalização}

Os processos de revitalizações urbanas não são recentes. Eles ocorrem desde o pósguerra, entre os anos de 1945-1975, que antecederam as mudanças contemporâneas das 
chamadas revitalizações urbanas. Entretanto, no período mencionado o intuito foi desenvolver um modelo econômico que estivesse ligado ao projeto de Estado e políticas sociais que almejavam uma reestruturação econômica e social, ou seja, de ordem urbana. Nesse contexto, as cidades passaram a protagonizar o crescimento econômico de matriz fordista.

No final do século XX, com a crise do modelo fordista, surgiram as novas demandas sobre as renovações e revitalizações das antigas áreas, que se acentuaram até a atualidade. Por volta da década de 1970, devido ao envelhecimento e decadência econômica de certas áreas herdadas do modelo fordista, também decadente, é que surgiram diversas áreas urbanas denominadas vazios urbanos, friches urbaines, friches industrielles, ou ainda os brownfields Vasques (2006); Couto (2014).

Com base em uma breve pesquisa sobre as revitalizações urbanas, já se torna evidente que existem áreas abandonadas, subutilizadas pelo mundo. Cabe destacar os pioneiros casos de cidades europeias e norte-americanas que, diante da decadência das relações políticoeconômicas, impulsionaram grandes projetos de retomada de áreas urbanas, porém algumas caíram na obsolescência total ou parcial. As intervenções urbanas em algumas cidades norteamericanas e europeias são emblemáticas e, até os dias atuais, servem como modelos para os projetos de revitalizações para o mundo. As revitalizações pioneiras em Boston, Baltimore e São Francisco (EUA), seguidas de Londres e Glasgow (Grã-Bretanha), Barcelona e Bilbao (Espanha), Berlim e Hamburgo (Alemanha), são exemplos frequentes para os planejadores.

No Brasil, encontram-se inúmeros casos, principalmente nos últimos trinta anos do século XX. Os casos como o Porto Maravilha, no Rio de Janeiro/RJ e o projeto Estação das Docas, em Belém do Pará/PA (Figura 1) são exemplos claros de grandes investimentos e conversões de áreas portuárias retomadas pelos processos de revitalizações em frentes d'água. No mesmo caminho, no Rio Grande do Sul, a inauguração em julho de 2018 da primeira fase concluída do Cais Mauá, na capital Porto Alegre é emblemática. 
Figura 1 - Estação das Docas (E) e Porto Maravilha (D)

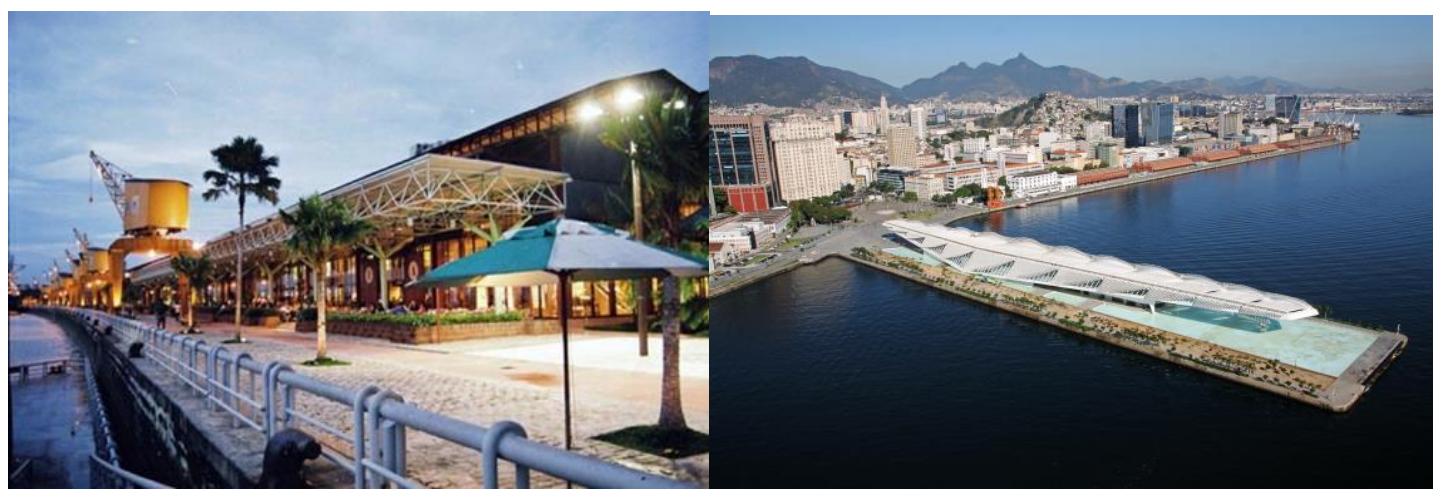

Fonte: Disponível em: http://www.anandrao.com.br/turismo/restaurantes/item/4631-estacaodas-docas e http://www.portomaravilhario.com.br/fotos_videos/g/22. Foto: Bruno Bartholini Acesso em agosto de 2018 .

Tal modelo de economia global trouxe consigo o sistema conceituado como flexível e de desregulamentação, o qual passa a ser articulado com a cidade, com as questões urbanas. Segundo Guerra (2006), esse novo modelo acarreta repercussões, ou seja, mutações econômicas e sociais que são diretamente refletidas nas estruturas urbanas, bem como podem ser constatadas pelas áreas obsoletas encontradas, revitalizadas e outras em vias de revitalização.

Seguindo na mesma direção, o conceito de revitalização encontra na literatura especializada outros conceitos vinculados, tais como: renovação, reabilitação e requalificação urbana. No entanto, a revitalização será o conceito discutido neste artigo, devido ao conteúdo processual e integrador. Sendo assim, tem-se que as revitalizações urbanas integram tanto funções urbanas, quanto parcerias (em geral, de cunho público-privado), bem como recursos. Acima de tudo, todos os demais conceitos, inclusive o de revitalização, possuem como diretriz a mesma palavra de ordem que é a intervenção urbana. Todavia, os conceitos supracitados podem integrar uma intervenção mais ampla de revitalização urbana (Moura, 2006).

Por fim, as revitalizações urbanas promovem a integração e/ou articulação entre as dimensões funcionais, culturais, simbólicas, visto que projetos bem formulados podem contribuir para o resgate ou permanência da memória e identidade do local. Entre as questões mais discutidas sobre a temática das revitalizações apresentam destaque aquelas que são pertinentes para o patrimônio histórico, ou seja, as memórias sociais e da cidade, presentes 
nas formas urbanas que são resultado de processos que remetem à produção do espaço, à dinâmica urbana e às metamorfoses espaciais.

No entanto, a escala do local em consonância com demandas globais que se encontram cada vez mais presentes nos espaços urbanos passam a interagir por meio das mídias digitais. Tal fenômeno contemporâneo pode ter sua expressão máxima nas promoções das cidades e de fragmentos provenientes da atividade turística. Assim, as revitalizações urbanas, em destaque nos casos das frentes d'água, são locais que possuem apelo paisagístico, histórico, cultural e que, em geral, integram esses elementos em nome da identidade.

A apropriação de tributos culturais por atores distintos ao local, sem a participação da população civil de forma efetiva nos projetos de revitalizações pode distorcer e até mesmo "reinventar" a memória da cidade. Por exemplo, na cidade de Blumenau, em nome do resgate do passado, recriaram-se infraestruturas, bem como cenários urbanos vinculados às tradições alemãs. No caso das cidades portuárias, que representam as relações marítimas ou ribeirinhas, recriam-se as relações com a água, em nome do passado, os espaços de "contato" na interface (água-cidade) encontram-se expressões contemporâneas que pouco se relacionam com o passado efetivo.

\section{As frentes d'água no contexto das revitalizações}

De um modo geral, as cidades portuárias possuem características próprias, mas também apresentam relações interescalares no e do desenvolvimento urbano. Pressupõe-se que apresentem diferentes resultados da produção socioespacial quanto às particularidades, mas que não estão dissociadas das instâncias, principalmente políticas e econômicas nas demais escalas (regional, nacional e global). Dessa forma, têm-se de um lado, as análises sobre a escala do local (intraurbano), as relações próximas de usos e ocupações pela população local, pela sociedade civil e com ela a produção espacial pela práxis. Por outro, as relações globais representadas aqui nesta pesquisa acerca de elaborações de projetos genéricos que partem do pressuposto da mercadorização do espaço. Desse modo, na perspectiva funcional do espaço, a cidade representa a mercadoria com valor de troca e, portanto, como produto a ser consumido. Nesse sentido, sobre a relação entre a história e a memória da cidade, e a dinâmica espaço-tempo, Abreu destaca: 
[...] é fundamental que não esqueçamos jamais que a história de um lugar é resultado da ação, num determinado momento e sobre um determinado espaço, de processos que atuam em escalas que são ao mesmo tempo desiguais e combinadas. Assim, a história de um lugar não pode se ater apenas aos processos puramente locais que aí tiveram efeito. Ela precisa relacioná-la a processos mais gerais, que atuam em escalas mais amplas (regional, nacional, global) da ação humana. (ABREU, 1998:21)

Nesse contexto, parte-se do pressuposto de que as cidades portuárias apresentam estruturas semelhantes desde sua gênese, o que pode ser constatado por meio dos diversos projetos de revitalizações portuárias estudados, indicando que eles estão atrelados a um modelo hegemônico de cidade enquanto mercadoria.

A discussão está voltada para a questão da constituição e legitimação de paradigmas relativos à reestruturação urbana em escala global. Novos paradigmas, mundializados, que emergem em processos de luta simbólica, são associados às condições históricas e políticas atuais da produção do espaço. Os atores que buscam ocupar posições hegemônicas na enunciação de discursos e na produção de "modelos" procuram impor determinadas categorias de leitura e de representação do urbano, que, por sua vez, influenciam outros atores, em relações transescalares, na definição de estratégias espaciais e na orientação das ações voltadas à produção da cidade-mercadoria (SÀNCHEZ, 2010:42).

Entretanto, ao planejar tais áreas, é preciso observar as relações de usos e apropriações de ordem próxima. São essas relações que possibilitam a compreensão, a partir da memória coletiva, do patrimônio cultural, sobre as mudanças nas atividades portuárias e a parcial ou total ociosidade das antigas áreas. Essas mudanças que trazem no bojo as relações globais referentes à economia, pelo rompimento dos paradigmas econômicos e tecnológicos, explicam, em parte, o movimento dialético do espaço urbano. Tal movimento, ao mesmo tempo, desigual e combinado que conduz às transformações espaciais em diferentes localidades, seja na Europa, seja no Brasil, os produtos de revitalizações urbanas serão distintos. Assim, Galimberti (2014) contribui para o debate sobre a retomada das frentes d’água nas cidades portuárias:

A partir de los câmbios em los modos de producción y de las lógicas del sistema capitalista - entre outras causas -, las ciudades costeras productivoportuarias afrontam diversas transformaciones. La desindustrialización, la incorporación de nuevas tecnologias y el cambio en las estructuras económicas dejam grandes áreas - portuárias, industriales y ferroviárias em desuso. Aparecen nuevos espacios expectantes de tranformación en sectores urbanos centrales estratégicos. Muchas ciudades ribereñas em todo el mundo desde mediados de las décadas de 1970, llevan adelante proyectos 
de renovación de estos frente fluviales a fin de reintegrar nuevamente la trama urbana com el rio (GALIMBERTI, 2015: 43).

Essas transformações possuem em seu conteúdo as relações sócioespaciais de apropriação e (re)apropriação dos espaços urbanos em diferentes temporalidades, o que resulta em diferentes espaços no que tange às funções urbanas e, assim, tornam visíveis, para além dos usos, as diferentes representações do espaço social. Nesse caso, ocorre a representação pelo espaço mercadoria e a apropriação da história, em contrapartida ao espaço com significativa representação pela memória para a então construção real da identidade local. Torna-se relevante considerar a preservação da memória social, a qual proporciona legibilidade à cidade e resgata sua cultura e identidade (COUTO, 2014).

Para contextualizar as transformações atuais com o processo histórico, no que tange às atividades portuárias e sua importância, o Quadro 1 mostra-se elucidativo.

Quadro 1. A relação cidade - porto em períodos distintos

\begin{tabular}{|l|l|l|}
\hline Relação com a interface & Período & Caracterização \\
\hline Cidade - porto & $\begin{array}{l}\text { Da idade } \\
\text { medieval ao } \\
\text { século XIX }\end{array}$ & $\begin{array}{l}\text { União funcional e espacial entre } \\
\text { cidade e porto. }\end{array}$ \\
\hline Expansão da cidade & $\begin{array}{l}\text { XIX ao } \\
\text { início do XX }\end{array}$ & $\begin{array}{l}\text { Rápido crescimento comercial e } \\
\text { industrial do porto para além dos } \\
\text { limites da cidade. }\end{array}$ \\
\hline $\begin{array}{l}\text { Cidade porto industrial e } \\
\text { moderna. }\end{array}$ & $\begin{array}{l}\text { Meados do } \\
\text { século XX. }\end{array}$ & $\begin{array}{l}\text { Crescimento industrial, } \\
\text { principalmente das refinarias de } \\
\text { petróleo, e introdução dos } \\
\text { contêineres e implicam separação } \\
\text { entre cidade e porto. }\end{array}$ \\
\hline Afastamento do porto & $\begin{array}{l}\text { Dos anos de } \\
1960 \text { até os } \\
\text { anos 1980 }\end{array}$ & $\begin{array}{l}\text { Inovações tecnológicas em } \\
\text { termos de atividades marítimas } \\
\text { que aumentam a separação entre } \\
\text { a cidade e o porto. }\end{array}$ \\
\hline $\begin{array}{l}\text { Redesenvolvimento da } \\
\text { frente de água. }\end{array}$ & $\begin{array}{l}\text { De } 1980 \text { aos } \\
\text { anos } 1990 .\end{array}$ & $\begin{array}{l}\text { Porto moderno ocupa grandes } \\
\text { extensões de terrenos. } \\
\text { Regeneração urbana da primitiva } \\
\text { relação cidade frente de água. }\end{array}$ \\
\hline $\begin{array}{l}\text { Revalorizações das } \\
\text { estruturas portuárias } \\
\text { primitivas. Resgate das } \\
\text { velhas formas regidas por } \\
\text { "novas" funções. }\end{array}$ & $\begin{array}{l}\text { De } 1990 \text { a } \\
2010\end{array}$ & $\begin{array}{l}\text { Avanço, intensificações nos } \\
\text { processos de revitalizações em } \\
\text { areas obsoletas e/ ou degradadas. } \\
\text { Inúmeros casos encontrados pelo } \\
\text { mundo. } \\
\text { Retorno as áreas portuárias } \\
\text { obsoletas sobre nova ótica de } \\
\text { valorizações com funções } \\
\text { distintas das fases anteriores. } \\
\text { Turismo, lazer, hotelaria, } \\
\text { valorização paisagistica. } \\
\text { Novas funções urbanas. }\end{array}$ \\
\hline \hline
\end{tabular}


Fonte: HOYLE B. S., PINDER, D. A. e HUSAIN, M. S, 1994. Revitalising the waterfront. London: Belhaven Press. Reelaboração, tradução e atualização pelas autoras.

Veremos, então, de forma sintética, alguns casos já estudados em diferentes continentes (Quadro 2) e que seguem a mesma tendência quanto à gestão, ao ordenamento e aos investimentos vinculados às parcerias público-privadas. Além disso, o que se observa como ponto comum é que as cidades e as áreas portuárias, em específico, possuem grande potencial. Podemos ainda acrescentar que realizar projetos que contemplem os diversos usos para diversas classes sociais são um compromisso, para com a história das cidades e de seus habitantes, fruto dos processos de produção e reprodução do espaço geográfico e, nestes casos, na escala do urbano.

Quadro 2. Alguns estudos de casos de revitalizações em frentes de água na Europa e América Latina

\begin{tabular}{|c|c|c|}
\hline ESTUDOS DE CASOS & ATORES & ASPECTOS POSITIVOS E NEGATIVOS \\
\hline \multicolumn{3}{|l|}{ EUROPA } \\
\hline $\begin{array}{l}\text { ROTTERDAM - } \\
\text { ROTTERDAM / } \\
\text { HOLANDA }\end{array}$ & $\begin{array}{l}\text { A forte tradição de } \\
\text { planificação nacional da } \\
\text { Holanda sobre usos do } \\
\text { solo ocasiona que as } \\
\text { intervenções } \text { de } \\
\text { renovação abordadas no } \\
\text { nível local se encontrem } \\
\text { intimamente articuladas } \\
\text { nos diferentes níveis } \\
\text { estatais. Não apresenta } \\
\text { iniciativas isoladas de } \\
\text { transformações por parte } \\
\text { da iniciativa privada. } \\
\text { Tem o componente } \\
\text { principal de investimento } \\
\text { público no processo de } \\
\text { conquista do solo ao } \\
\text { longo do rio. A } \\
\text { transformação } \\
\text { promovida de forma } \\
\text { integral pela cidade em } \\
\text { correspondência com as } \\
\text { políticas de planificação } \\
\text { nacional. }\end{array}$ & $\begin{array}{l}\text { Positivos: a continuidade do planejamento estatal possibilita a a } \\
\text { integração de diversas necessidades e requerimentos, produto } \\
\text { tanto da expansão urbana quanto da expansão produtiva. Assim } \\
\text { mesmo, as transformações das áreas obsoletas centrais da cidade } \\
\text { também são parte dessa planificação pública integrada em } \\
\text { concordância com as políticas de planificação nacional - o que } \\
\text { possibilita evitar intervenções isoladas que persigam unicamente } \\
\text { interesses privados. É por meio do apoio, do financiamento, da } \\
\text { gestão integrada entre os diferentes níveis governamentais que se } \\
\text { possibilita a sua concretização. } \\
\text { Negativos: diversas frentes ainda indicam que este projeto tende } \\
\text { a gerar um processo de "Manhatização" comparando com } \\
\text { Manhattan (EUA). É acusado de importar imagens exógenas e } \\
\text { transportá-las para o local. Não obstante, por parte da } \\
\text { planificação local responde a essas críticas sustentando que se } \\
\text { incorpora ao projeto: a recuperação de parte do patrimônio } \\
\text { industrial, da criação de novos equipamentos e serviços, a } \\
\text { construção de novos espaços públicos e a integração de bairros } \\
\text { populares. }\end{array}$ \\
\hline $\begin{array}{l}\text { IBA ENSCHER PARK - } \\
\text { BACIA DO } \\
\text { RUHR/ALEMANHA }\end{array}$ & $\begin{array}{l}\text { No estado federal da } \\
\text { Renânia do Norte- } \\
\text { Vestfália, destaca-se o } \\
\text { plano de } 1989 \text { do } \\
\text { Internacional } \\
\text { Bauaustellung Emscher } \\
\text { Park, mais conhecido } \\
\text { como IBA Emscher } \\
\text { Park, visando ampliar o }\end{array}$ & $\begin{array}{l}\text { Positivos: El IBA Emscher Park reforça a importância do olhar } \\
\text { integrado e contínuo dos processos de planificação, desde o } \\
\text { surgimento das iniciativas de transformação até o do controle } \\
\text { posterior das intervenções realizadas. Diversos temas, objetivos e } \\
\text { projetos se desenvolvem em numerosas localidades que abarcam, } \\
\text { mais de } 800 \mathrm{~km}^{2} \text {. Não obstante, esta "reconstrução paisagística", } \\
\text { como eles chamam essa gestão público-privada, há mais de duas } \\
\text { décadas de seu surgimento tem se transformado em caso } \\
\text { emblemático de transformação de regiões industriais degradadas }\end{array}$ \\
\hline
\end{tabular}




\begin{tabular}{|c|c|c|}
\hline & $\begin{array}{l}\text { desenvolvimento dessa } \\
\text { região em um período de } \\
10 \text { anos. The } \\
\text { International Building } \\
\text { Exhibition se constitui } \\
\text { como uma agência } \\
\text { privada subsidiada pelo } \\
\text { Estado. Essa organização } \\
\text { atua como motivadora e } \\
\text { moderadora dos projetos } \\
\text { e processos de } \\
\text { planificação propostos } \\
\text { pelos atores convidados } \\
- \text { quer dizer que não } \\
\text { propõe projetos próprios. } \\
\text { O IBA organiza a } \\
\text { utilização dos recursos } \\
\text { existentes, promove } \\
\text { redes, assegura a a } \\
\text { qualidade dos resultados } \\
\text { e articula as diferentes } \\
\text { propostas. }\end{array}$ & $\begin{array}{l}\text { no âmbito internacional. } \\
\text { Negativos: A forte tradição em planificação nacional da } \\
\text { International Building Exhibition, as valiosas e numerosas } \\
\text { instalações produtivas representantes da história alemã presentes } \\
\text { em toda região da bacia do Ruhr, o papel do Estado da Renânia } \\
\text { do Norte-Vestfália, a solvência econômica do Estado para levar } \\
\text { adiante estes projetos, entre outros fatores, ocasionam que este } \\
\text { exemplo seja difícil de transpor para outros contextos, } \\
\text { especialmente no âmbito latino-americano. }\end{array}$ \\
\hline \multicolumn{3}{|l|}{ AMÉRICA LATINA } \\
\hline $\begin{array}{l}\text { MALECON } 2000 \text { - } \\
\text { GAYAQUIL/EQUADOR }\end{array}$ & $\begin{array}{l}\text { Em janeiro de } 1997 \text { é } \\
\text { criada a Fundação } \\
\text { Malecon } 2000, \text { com } \\
\text { objetivo de ser a } \\
\text { entidade a cargo de } \\
\text { projetar, executar e } \\
\text { administrar o Malecon } \\
\text { 2000. Ela é uma entidade } \\
\text { privada, conformada por } \\
\text { atores públicos e } \\
\text { privados e presidida pelo } \\
\text { prefeito de Guayaquil. }\end{array}$ & $\begin{array}{l}\text { Positivos: converte-se o espaço mais degradado da cidade, } \\
\text { principalmente no foco do turismo, permitindo uma reconexão da } \\
\text { área urbana com o rio Guayas. A valorização dos espaços } \\
\text { públicos, a preservação patrimonial, a busca da identidade local, } \\
\text { a reativação do comércio da zona central, entre outros, } \\
\text { constituem temas chaves dos projetos que possibilitam sua } \\
\text { concretização e aceitação por grande parte da sociedade. Além } \\
\text { disso, o Porto foi a gênese na constituição de Malecon e por meio } \\
\text { da revitalização volta a ser o principal perfil da cidade. } \\
\text { Negativos: A resposta da gestão municipal é que sob a pressão de } \\
\text { fatores políticos e econômicos, o processo de revitalização leva à } \\
\text { lógica mercantilista que favorece determinados setores privados e } \\
\text { não permite a participação cidadã ativa no projeto. Tal fator } \\
\text { ocasiona que objetivos iniciais e diretrizes do projeto não possam } \\
\text { ser levadas a cabo integralmente. A gestão do Malecon } 2000 \\
\text { oculta fortes contradições como o enfraquecimento da ação } \\
\text { pública diante das políticas privatizadoras do projeto. }\end{array}$ \\
\hline
\end{tabular}




\begin{tabular}{|c|c|c|}
\hline $\begin{array}{l}\text { PUERTO MADERO } \\
\text { BUENOS } \\
\text { AIRES/ARGENTINA }\end{array}$ & 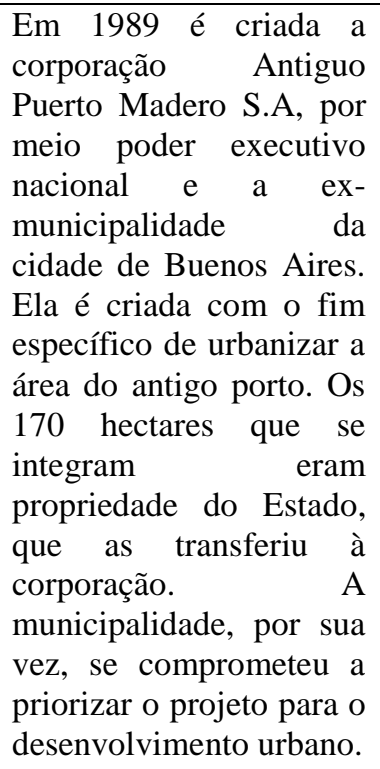 & $\begin{array}{l}\text { Positivos: o setor do Puerto Madero se converte na principal } \\
\text { imagem de Buenos Aires, posicionando a cidade como foco de } \\
\text { atração turística no âmbito internacional incorporando grande } \\
\text { quantidade de hectares para espaço público. } \\
\text { Negativos: o forte papel dos promotores privados ocasiona uma } \\
\text { "gestão empresarial" da administração pública. A importação de } \\
\text { modelos norte-americanos e europeus de "corporações" } \\
\text { encarregadas da transformação dos enclaves, em um contexto } \\
\text { latino-americano de desigualdade social e inequidades } \\
\text { socioterritoriais, produz efeitos mais complexos em relação à } \\
\text { conexão cidade/rio e à formação de espaços públicos urbano- } \\
\text { territoriais de acesso para toda a sociedade e não só para grupos } \\
\text { hegemônicos da elite. }\end{array}$ \\
\hline
\end{tabular}

Fonte: GALIMBERTI, 2014. Reelaboração, adaptação e tradução das autoras.

No caso das principais revitalizações de áreas portuárias no Brasil, a Estação das Docas na cidade de Belém (PA) e o Porto Maravilha na cidade do Rio de Janeiro (RJ), ambos os projetos possuem como elemento fundamental o conceito de Operação Urbana Consorciada (OUC), ou seja, um instrumento previsto no Estatuto da Cidade (Lei $n^{\circ} 10.257 / 2001$ ), que permite a realização de um conjunto de intervenções e medidas coordenadas por um município, com participação dos proprietários, moradores, enfim, usuários e investidores privados, com o objetivo de alcançar, em área específica, transformações urbanísticas de infraestrutura, melhorias sociais e a valorização ambiental. Esse dispositivo permite parcerias entre o poder público e a iniciativa privada em conjunto com os moradores e usuários de tais áreas. Pode-se constatar, de forma crítica, a prevalência da concessão de exploração do espaço público por parte da iniciativa privada e que a participação popular, quando acontece, é proveniente de representante dos movimentos sociais, visto que a participação direta é pouco usual em tais processos.

Nessas intervenções, com base no conceito de operação urbana consorciada, o bônus para o Poder Público seria o aumento do coeficiente de aproveitamento e/ou de "novos" ou ainda diferentes usos das áreas alvo das revitalizações. Dessa forma, as vantagens concedidas aos proprietários privados em troca de uma contrapartida, podem ser de ordem econômica ou ainda a criação de espaços públicos ou para fins de habitação de interesse social, ou seja, são 
meios compensatórios pelos usos da iniciativa privada. Por isso, Serpa (2007) evidencia as relações entre os interesses públicos e privados:

Como participante de parcerias entre o público e o privado, nos campos da arquitetura, do urbanismo e do paisagismo, o Estado coloca em ação estratégias urbanas que não conseguem ultrapassar os limites de sua própria sombra. Desse modo são produzidos, apenas, lugares de expulsão e de extradição (SERPA, 2007: 38).

Em linhas gerais, as novas funções urbanas abarcam modelos de projetos de conversão que primam por atividades turísticas e de lazer, em nome da ocupação do espaço público. Tais exemplos indicam mudanças nas formas de apropriação do local, a partir de novas funções, no caso, dos moradores para turistas ou ainda moradores em busca do lazer, comércio, dentre outros.

Uma das principais questões trazidas ao debate é para quem os projetos são desenvolvidos e o grau de envolvimento dos idealizadores com a história local e em simbiose, com a reutilização das infraestruturas existentes. Por intermédio desses elementos surge o questionamento se os interesses metropolitanos diferem dos interesses de cidades de menor porte, como o caso das cidades médias e até mesmo das pequenas, partindo-se do pressuposto de que, indiferentemente a escala, a lógica contemporânea de apropriação dos diversos atributos contidos em cada formação urbana é eminentemente parte do processo global. Em contrapartida, existem interesses na preservação do patrimônio que, muitas vezes, entram em conflito com os interesses dos agentes econômicos privados. Pode-se eleger como exemplo os agentes imobiliários que, de certa forma, contribuem para valorizar áreas degradadas em nome da cultura local e, assim, são criados cenários em que se forja uma identidade local desvinculada da realidade.

\section{As cidades portuárias, as revitalizações nas frentes d'água e a memória urbana}

Nos casos das revitalizações nas frentes d'água, encontramos conflitos que abarcam questões urbanas em um conjunto de fatores, sejam ambientais, valorização especulativa do solo urbano, a pouca ou inexistente participação da população local, as atividades turísticas, entre outros. Assim, parte-se para o debate sobre a memória urbana, ancorada nas relações em diferentes escalas de análise geográfica e a sua influência nos modelos de cidade. Da cidade portuária primitiva projeta-se uma cidade portuária contemporânea e a apropriação dos atributos inerentes destes velhos/novos espaços. 
O quadro geral das revitalizações em frentes de água apresenta uma tendência contemporânea de lucrar em nome dos atributos paisagísticos, históricos, o patrimônio artístico e cultural, elementos comuns entre as cidades portuárias. Para tanto, reestruturar partes da cidade sob a ótica conjunta, que envolve a sua revitalização (renovar e preservar) e a memória, pressupõe o entendimento sobre o uso e valorização que tal espaço obteve em diferentes tempos. Por isso, entre a preservação da efetivação da memória e a contemporaneidade sob a égide da renovação urbana, obtém-se a reinvenção da cidade.

Portanto, é por meio das investigações sobre as revitalizações e dos novos usos que emerge o debate que evoca o passado sob novas roupagens, bem como a simbiose entre o passado e as novas funções resulta nas metamorfoses espaciais. Recuperar o passado não é, entretanto, repetir o tempo, mas reinventá-lo. Nesse contexto, processo e dinâmica são as palavras de ordem. No entanto, a memória evoca relações entre passado e presente, bem como abrange as múltiplas concepções entre a memória da cidade que pode ser interpretada a partir de diferentes grupos sociais. Ao tratar da memória social da cidade sob o olhar do espaço portuário, vale registrar a existência dos trabalhadores, dos imigrantes, dos escravos, os quais se relacionaram com este espaço em diferentes períodos históricos. Por isso, pressupõe-se que, no presente, o planejamento da área portuária expresse tal palimpsesto sob a responsabilidade de retratar a memória desses diferentes atores sociais. Sendo assim, esse espaço foi constituído coletivamente e permanece enquanto objeto de disputa simbólica revelando os diferentes interesses entre o que preservar e como. Com isso, revela-se a difícil tarefa de planejar áreas históricas que, no plano das representações, orientam os diferentes interesses e, por conseguinte, abre-se o campo dos conflitos entre interesses coletivos dos diferentes usos.

Uma das questões mais discutidas sobre os impactos causados pelas revitalizações é a gentrificação. $\mathrm{O}$ processo de gentrificação ${ }^{4}$ é uma intervenção que impacta profundamente o local, desde a mudança radical dos costumes, alterando-se a paisagem e os usuários dessas áreas, rompendo-se com as tradições da vida cotidiana, ou seja, viabilizam-se novas práticas espaciais.

\footnotetext{
${ }^{4}$ Fenômeno entendido como segregador. Por isso, propomos um avanço a partir do qual os elementos serão indissociados: moradia, trabalho, lazer e consumo. Assim, além de indissociáveis eles estão conectados às transformações da paisagem urbana.
} 
É a partir do olhar sobre a divisão do trabalho que podemos analisar se tais espaços, de acordo com as políticas e os projetos articulados à sua reanimação, em sua maioria, de caráter público, incentivam a inclusão ou a exclusão da população local ou ainda sobre a proeminência do processo de segregação sócioespacial. Quem frequentará e se beneficiará das infraestruturas implementadas? Quem será o detentor dos meios e dos bens lucrativos, como hotéis, restaurantes, enfim, estabelecimentos comerciais instalados como aparato urbanístico e turístico? É nesse contexto que encontramos o conflito, ou seja, áreas passíveis de serem valorizadas, elitizadas e à mercê do processo de gentrificação, que remete a uma "[...] mudança social e à paisagem cultural da cidade associada a uma geografia econômica em plena mudança" (SMITH, in BIDOU-ZACHARIASEN, 2006:63).

Sobre essa retomada de áreas desvalorizadas e a reabilitação de espaços urbanos obsoletos, sobre o ponto de vista da gentrificação, é que aqui a denominamos como gentrificação generalizada:

Agora são mais que edifícios e habitações reformados e reabilitados, a gentrificação se manifesta nos equipamentos de serviços, comércio, lazer e cultura, produzindo paisagens e espaços urbanos que podem ser consumidos como fala Smith no trecho abaixo: "A gentrificação produz agora paisagens urbanas que as classes médias e médias altas podem consumir... e que contribuem para a formação de identidades de classe através de um espectro de classes significativo, ainda que de maneiras muito diferenciadas" (SMITH in BIDOU-ZACHARIASEN, 2006:73).

Dessa forma, as cidades portuárias passam por transformações, que devemos considerar pelo viés da dialética urbana, visto que os corpos d'água foram e ainda são fundamentais para a construção e desenvolvimento das cidades e da cultura que, de certa forma, os mantêm como elementos identitários dos núcleos urbanos em áreas costeiras. Com base no contexto em voga, entre o global e local, tem-se que:

A discussão está voltada para a questão da constituição e legitimação de paradigmas relativos à reestruturação urbana em escala global. Novos paradigmas, mundializados, que emergem em processos de luta simbólica, são associados às condições históricas e políticas atuais da produção do espaço. Os atores que buscam ocupar posições hegemônicas na enunciação de discursos e na produção de "modelos" procuram impor determinadas categorias de leitura e de representação do urbano, que, por sua vez, influenciam outros atores, em relações transescalares, na definição de estratégias espaciais e na orientação das ações voltadas à produção da cidade-mercadoria (SÀNCHEZ, 2010:42).

Repensar a organização desses espaços também significa repensar a cidade, pois geralmente as frentes d'água são as matrizes culturais, ou seja, a gênese da urbanização, a válvula propulsora das atividades não só econômicas, mas principalmente da relação 
simbiótica com a sociedade de usos em diferentes períodos de tempo e, consequentemente, de identidade também cultural.

Ao partirmos da hierarquia espacial, produto das apropriações pela diversidade das classes sociais, logo dos prováveis usuários, evidencia-se a complexidade e as diferenças nas formações socioespaciais. As relações territoriais contemporâneas perpassam e ultrapassam as relações no território enquanto Estado-Nação, dos limites com fronteiras definidas, e, a partir disso, surge a complexidade entre os territórios, uma amálgama de dominância simbólica e de dominância funcional, que apresenta, concomitantemente, relações conflitantes, desiguais e combinadas. Sobre o consumo do espaço seguindo a lógica mercadológica, ao nos referirmos ao território enquanto "invólucro" que contém e assume simbologias, assim podemos definilo como o espaço produzido. Para melhor compreender as relações funcionais e simbólicas, o Quadro 3 busca simplificar as suas relações no contexto das dimensões espaciais.

Quadro 3. Dimensões espaciais

\begin{tabular}{|c|c|}
\hline \multicolumn{2}{|c|}{ Dimensões espaciais } \\
\hline Funcional & Simbólica \\
\hline Unidade territorial & Multiplicidade territorial \\
\hline Local & Atividades artificiais/simbólicas \\
\hline Atividades lucrativas/recurso & Valor de uso \\
\hline Valor de troca & Unidade espacial \\
\hline Diferenciação espacial & Espaço público, de unidade \\
\hline Espaço diferencial, de segregação & Coesão \\
\hline Fragmentação & Atributos culturais \\
\hline Atributos políticos/ econômicos & \\
\hline
\end{tabular}

Fonte: Elaborado pelas autoras (2018).

Em contrapartida, as frentes d'água possuem o potencial inestimável quanto às atividades contemporâneas de lazer, de projetos que se voltam para o cais. Posto que, em outros momentos, em períodos de estagnação econômica, as cidades encontravam-se de costas paras essas áreas. Assim, a cidade, ao se distanciar do cais, negava as origens diante da ideologia da modernidade em que o efêmero é a palavra de ordem, além da contração do espaço-tempo e da ruptura das relações sociais construídas na escala local. No entanto, como 
resultado deste processo modernizador e também com as friches urbaines surgem as lacunas na memória da cidade.

As áreas ditas obsoletas trazem à luz a possibilidade da retomada dos elementos históricos e culturais contidos na paisagem. Esses elementos estão presentes em suas formas e funções e no processo de formação urbana e, portanto, revelam a memória e a identidade da cidade.

Ainda sobre a relação entre a estruturação da cidade e suas frentes d'água, encontramos em Da Costa (2009):

\begin{abstract}
As frentes portuárias provaram ser, ao longo dos séculos, de grande importância para as cidades, não só em termos de ligação e comércio com outras cidades, ou de descoberta e conquista de novos territórios, mas também como elemento identitário e cultural. O crescimento conjunto das cidades e dos respectivos espaços portuários passaram por fases de proximidade e de afastamento, sendo o séc. XIX o momento mais marcante para a quebra de relações entre a cidade e a sua frente d'água, deixando profundas cicatrizes no tecido urbano. Nas últimas décadas tem-se procurado um planeamento funcional que recuperasse a ligação da cidade ao seu porto, criando diversas dúvidas sobre a manutenção do legado portuário mercantil, ou alteração para novos usos e funções que possam servir directamente os cidadãos (DA COSTA, 2009:10).
\end{abstract}

Na revitalização urbana, uma parte dos agentes do espaço planeja-o de acordo com o momento histórico e com as "necessidades" de uso, assim como as demandas do sistema. A ideia de ação é possível relacionar ao processo que modifica determinado espaço e no qual estão contidas as relações políticas, econômicas, sociais, culturais e ideológicas; isto é, espacialidades que modelam determinados espaços de acordo com o seu tempo.

Ainda no tocante à memória, tornam-se significativas as palavras de Halbwachs (1990): não há memória coletiva que não se desenvolva num quadro espacial". Por isso, as revitalizações devem - ou deveriam - considerar a história e a memória das cidades, ou seja, das localidades a serem revitalizadas. Em muitos casos, no processo de gentrificação, os agentes econômicos envolvidos diretamente se apropriam de tais particularidades, principalmente em nome da cultura, muitas vezes forjada para atribuir valor aos espaços, com a finalidade do consumo do mesmo, em especial no caso da conversão para o turismo. Diante desta perspectiva, consideramos que revitalizar não significa o mesmo que conservar, embora não se deva descartar a hipótese, o olhar sobre questões patrimoniais e culturais que garantem a identidade de um povo e de sua cultura. 
As mudanças acarretadas nas atividades portuárias figuram como um bom exemplo da influência da ação de outras instâncias políticas que se estendem além da escala local, visto que o espaço urbano costuma ser regido por políticas econômicas globais, nacionais e regionais. Vale ressaltar que, embora essas mudanças não tenham sido ditadas localmente, mas em outras escalas, pela economia elas acarretarão mudanças na cidade, pois estarão relacionadas com a história do mundo e da nação, ou seja, dos processos mais gerais. Isso possibilitará uma leitura única da cidade, sem deixar de lado o processo histórico e seu conteúdo como um todo. Em relação à história e à memória, Abreu destaca:

[...] é fundamental que não esqueçamos jamais que a história de um lugar é resultado da ação, num determinado momento e sobre um determinado espaço, de processos que atuam em escalas que são ao mesmo tempo desiguais e combinadas. Assim, a história de um lugar não pode se ater apenas aos processos puramente locais que aí tiveram efeito. Ela precisa relacioná-la a processos mais gerais, que atuam em escalas mais amplas (regional, nacional, global) da ação humana. (ABREU, 1998: 21)

O passado faz parte do cotidiano das diversas sociedades contemporâneas por meio da memória e da história. Por isso, insistimos e destacamos a importância da investigação das particularidades e especificidades de cada local de estudo. Essas memórias urbanas não se constituem apenas do estoque de lembranças, ou seja, da história da cidade que, por sua vez, não é neutra:

Independentemente de qual tenha sido o estoque de materialidades históricas que tenham conseguido salvar da destruição, as cidades do país vêm hoje engajando-se decisivamente num movimento de preservação do que sobrou de seu passado, numa indicação flagrante de que muita coisa mudou na forma como a sociedade brasileira se relaciona com as suas memórias. (ABREU, 1998:21)

$\mathrm{Na}$ geografia urbana, especificamente sobre estudos das revitalizações, as materialidades fornecem ferramentas que permitem contribuir com as pesquisas, de forma que tais locais possam ser reanimados com usos que atendam às necessidades tanto econômicas e estruturais da sociedade quanto o uso pelo turismo. Essa relação se efetiva e também legitima as relações sociais no tempo e no espaço. Continuamos com Abreu e suas contribuições relativas à cidade e à memória:

Mas a cidade não é um coletivo de vivências homogêneas. Para definir o que seria a memória das cidades, nossa categoria de análise não pode ser a população. O que faz com que surja uma memória grupal ou social, referida a algum lugar, é o fato de que aquele grupo ou classe social estabeleceu ali 
relações sociais. Essas relações, entretanto, podem ser de dominação ou de conflito e variam tanto no tempo quanto no espaço. (ABREU, 1998: 28)

Para isso, no âmbito da gestão, é necessário um planejamento prévio, adequado que atenda a demanda de serviços para, assim, gerar renda (trabalho) à população ao mesmo tempo em que contemple as relações sociais construídas ao longo do tempo, na localidade em destaque. As relações mencionadas vêm associadas aos "novos" e/ou diferentes usos e apropriações, às novas demandas sociais, seja para fins de moradia, turismo ou ainda para outras funções que cumpram, de fato, a função social da propriedade urbana e não a função social da propriedade privada (a terra como mercadoria). Por outro lado, a partir dos processos de valorização, via revitalizações, temos, como resultado, a possibilidade de novos usos, principalmente na contemporaneidade, mesmo quando o Estado e a iniciativa privada são aliados na (re) produção espacial, de alguma forma privatizadora de espaços até então públicos.

Existem diferenciações sutis quanto à lógica de valorização espacial, pois não há remoção efetiva de contingente de usuários como em áreas destinadas à iniciativa privada, a exemplo dos shoppings que, apesar de passarem o ideal de espaço público, constituem locais de livre consumo, porém de domínio privado. Nesses casos ocorridos em áreas destinadas à moradia ou à mudança radical de usos de determinadas áreas urbanas, alvo de especulação para a valorização, a expulsão é explícita. No entanto, no caso dos espaços públicos o processo se mostra de maneira sutil, com a expulsão ocorrendo em função do poder aquisitivo do usuário. Portanto, um retorno que busca esclarecer melhor a memória urbana, elemento importante na análise desses processos e das cidades que, muitas vezes, figura como "objeto" que serve para agregar valor. Por isso, são importantes as palavras de Abreu:

[...] a verdade é que os termos "memória urbana" e "memória das cidades" vingaram e dizem respeito não a capacidade de lembrar de indivíduos ou grupos, mas ao estoque de lembranças que estão eternizados na paisagem ou nos registros de um determinado lugar, lembranças essas que são agora objeto de reapropriação por parte da sociedade [...] Distinguiremos, entretanto, a "memória urbana", que ao nosso ver trata do estoque de lembranças do modo de vida urbana per si, sem obrigação de relacioná-las a uma base material particular, a um lugar específico, e "à memória da cidade", que referencia obrigatoriamente essas mesmas lembranças a uma base material precisa, a um determinado lugar. Essa distinção é importante para que discutamos porque a história, que tanto pode contribuir para o resgate da memória de uma cidade, vem contribuindo tão pouco (ABREU, 2012:31). 
Nesses termos, os processos de revitalização portuária possuem como objetivo pressuposto, por trás da "revitalização", a revalorização e, em consequência disso, a (re) integração da cidade ao porto, o que aqui chamamos de interface. ${ }^{5}$ A referida ligação entre o porto e a cidade, ou melhor, a interface cidade-porto, pressupõe a (re)apropriação dessa espacialidade e, para tanto, a memória da cidade, bem como a memória urbana são importantes para o resgate, à reinserção ou ainda ao entendimento dos potenciais de usos adequados da localidade em foco. É nessa interface, no "cais do porto", que se estabelecem relações peculiares, as quais refletem, em parte, o cotidiano com maior aproximação das atividades que existiram e ainda existem nessa interface, atividades que produzem uma urbanidade voltada às atividades náuticas (pesca, travessia de pessoas por embarcações, o comércio no mercado público e arredores). No caso específico das atividades pesqueiras, a pesca artesanal, a pesca esportiva e também comércios tradicionais no local, como no caso dos mercados públicos e dos centros históricos, em geral formados adjacentes às antigas áreas portuárias. As remanescentes estruturas industriais também se fazem presentes em grande parte das cidades portuárias e são alguns exemplos do cotidiano, contidos na memória da cidade.

Portanto, são diversos os elementos representativos do cotidiano nas antigas cidades portuárias que, na atualidade, remetem ao que podemos denominar "memórias do cais", fazendo alusão ao trabalho de Torres (2009), o qual podemos associar à memória da cidade. Essa integração entre usos e usuários produz uma urbanidade própria, em nível pontual: no cais. Nele, como em nenhum outro ponto da cidade, é possível encontrar tais relações históricas, resultando no que encontramos ainda hoje nas formas, e nas estruturas portuárias.

\section{Considerações Finais}

Diante dos estudos realizados sobre os projetos e processos de revitalizações urbanas, existem elementos que são a chave para o planejamento de áreas obsoletas em solo urbano, ou seja, a conexão entre o passado, o presente e o futuro. Assim, aliada aos estudos de casos e à teoria pertinente ao tema, tem-se a contribuição e a compreensão das diversidades (formas, estruturas, funções) encontradas nos processos de revitalizações e na dinâmica urbana. Não

\footnotetext{
${ }^{5}$ Interface: local em que dois espaços se fundem e forma-se o limite comum entre ambos: a área do cais que proporcionou a simbiose entre cidade e a antiga estrutura portuária.
} 
obstante, os diversos estudos e reflexões sobre o tema, também trazem a contribuição sobre a produção do espaço urbano contemporâneo, sobre o viés das revitalizações e intervenções e suas implicâncias desde a elaboração e a implementação dos projetos, isto é, relações políticoeconômicas. Além disso, a elaboração dos projetos deve congregar diversas áreas do conhecimento como história, arquitetura, geografia, arqueologia, sociologia, entre outras, a fim de qualificar a análise diante da complexidade socioespacial e da diversidade dos seus potenciais de usos. No entanto, o que encontramos são processos homogêneos, do ponto de vista dos modelos de projetos para as cidades. Com isso, seus conteúdos constatam que, em geral, há pouca relevância no tocante à memória das cidades. Ao passo que, encontra-se alguma relevância sobre a memória coletiva e das cidades, ela vem atribuída ao patrimônio histórico e suas edificações.

A relação entre a memória e o patrimônio é recorrente, sendo apropriada pelas atividades turísticas, bem como é possível constatar distorções sobre os fatos históricos que, na maioria dos casos, não retratam a memória coletiva da diversidade dos estratos sociais. No caso das áreas portuárias, a ênfase sobre os imigrantes europeus, cosmopolitismo e as atividades econômicas são evidentes em detrimento da memória dos trabalhadores portuários, bem como de escravos, com destaque para a mão de obra que ergueu grande parte da estrutura urbana das cidades portuárias.

Diante dessa complexidade, têm-se as escalas de análises geográficas, que trazem as dimensões entre o global e o local, compreendidas como as ordens próxima e distante, sendo que a articulação entre elas é de fundamental importância no desenvolvimento dos processos espaciais. No caso das áreas portuárias, esta relação entre as escalas é intrínseca, devido ao fato dos portos representarem os fluxos tanto de mercadorias, de pessoas e, consequentemente, de cultura. A relação cidade-porto, que expressa características próprias destas formações urbanas, revela as relações entre as escalas e, ao mesmo tempo, o caráter cosmopolita de tais cidades, uma vez que foi por intermédio dos portos que ocorreram os fluxos migratórios de comerciantes, escravos (mão de obra) em todas as partes do mundo. Esses fluxos proporcionaram desenvolvimento urbano e caracterizaram a identidade das cidades portuárias, bem como das regiões nas quais estão inseridas. A pesquisa torna evidente que as áreas em obsolescência em grande parte dos casos utilizam o patrimônio histórico arquitetônico em nome da memória urbana a fim de obter lucros sobre a herança patrimonial e cultural (atribuição funcional e simbólica). No entanto, entre a teoria e a prática, entre o 
processo histórico e os projetos de revitalizações, estão os elementos que conduzem ao entendimento de que o espaço urbano é dialético e está em constante movimento de produção e reprodução, ou seja, o espaço historicamente produzido.

Em síntese, as cidades apresentam, no que se refere à valorização espacial, diversas facetas nas diferentes escalas de análise e diversos conteúdos socioespaciais. Sendo assim, as cidades que possuem como estratégia o turismo, também apresentam diferentes conteúdos representados pelos seus atributos: belezas cênicas naturais, patrimônio histórico, ou seja, as particularidades se tornam o conteúdo diferencial. No entanto, não se pode negligenciar o papel da mídia e de outros agentes econômicos, os quais criam, reinventam e "vendem" as cidades ou parcelas delas, além de reproduzirem modelos e projetos que, por vezes, deturpam a identidade local. Tendo em vista os aspectos observados nos processos de revitalizações urbanas, a análise realizada neste artigo foi conduzida sobre a fundamentação teóricometodológica entre as relações de escala global/local; ordem próxima e distante e a preservação e construção e apropriação da memória da cidade.

Diante da análise, foi possível concluir que o importante papel da memória das cidades e, no caso das cidades portuárias, as frentes d'água são o exemplo mister diante das relações contemporâneas de resgate da memória evocada pelos processos de refuncializações urbanas. Este resgate, por sua vez, representa que a memória está sendo produzida em um constante movimento e ancorada entre as memórias do passado entrelaçadas com as práticas espaciais no presente. Em suma, concordamos com Abreu (2012) que a memória de um lugar, a memória de uma cidade é, essencialmente, uma memória coletiva.

\section{Referências}

ABREU, Maurício de Almeida. Sobre a Memória das Cidades. Revista Território, Rio de Janeiro, v. 4, p. 5-26, $1998 . \quad$ Disponível em: http://www.revistaterritorio.com.br/pdf/04_2_abreu.pdf. Acesso em: 30 out. de 2010.

BIDOU ZACHARIASEN, Catherine. Introdução. De volta à cidade: dos processos de gentrificação às políticas de "revitalização" dos centros urbanos. São Paulo: Annablume, 2006.

CÂMARA MUNICIPAL DE LISBOA. Carta de reabilitação urbana integrada-Carta de Lisboa. In: I Encontro luso-brasileiro de reabilitação urbana de centros históricos. Câmara Municipal de Lisboa. Pelouro da reabilitação urbana dos núcleos históricos, Lisboa, 1995. Disponível em: chromeextension://oemmndcbldboiebfnladdacbdfmadadm/https://www.culturanorte.pt/fotos/e 
ditor2/1995_carta_de_lisboa_sobre_a_reabilitacao_urbana_integrada1\%C2\%BA_encontro_luso-brasileiro_de_reabilitacao_urbana.pdf < acesso: 15/08/2018. CORRÊA, R.L. Espaço, um conceito chave da Geografia. In: Castro, I.; Gomes, P.C.; Correa, R.L. (Org.) Geografia: conceitos e temas. Rio de Janeiro: Bertrand Brasil, 1995 . O espaço urbano. São Paulo: Ática, 1989.

COUTO, Perla Duarte. Revitalizações urbanas em espaços públicos: o porto Velho da cidade do Rio Grande/RS, tempos e funções distintas. Dissertação de mestrado. Universidade Federal do rio Grande - FURG, Rio Grande, 2014. Disponível em: http://www.argo.furg.br/bdtd/0000010592.pdf Acesso: 18/08/2018.

DA COSTA, Rita Bibe. Cidades d'água. Relação entre as cidades e suas frentes d'água. 110 p. Dissertação de mestrado. Instituto Superior Técnico Universidade Técnica de Lisboa. Lisboa 2009.

Disponível

em: $<$ https://fenix.tecnico.ulisboa.pt/downloadFile/395138347921/Cidades\%20de\%20\%C3\%81gua .pdf> Acesso: 18/08/2018.

GALIMBERTI, Cecilia. Reflexiones en torno a las transformaciones de waterfronts contemporáneas. Arquitectura y Urbanismo [on-line]. 2014, vol.35, n.2, pp. 19-35. ISSN 1815-5898. Disponível em: http://scielo.sld.cu/scielo.php?pid=S181558982014000200003\&script=sci_arttext Acesso: 22/08/2018.

GUERRA et al. Políticas Públicas de Revitalização Urbana-Revitalização para a formulação estratégica e operacional das actuações a concretizar no QREN. ISCTE/CET, Observatório do QCA III, 2005. Disponível em: chromeextension://oemmndcbldboiebfnladdacbdfmadadm/http://www.qren.pt/np4/file/1427/12_Pol_t icas_P_blicas_de_Revitaliza_o_U.pdf Acesso: 20/08/2018.

HALBAWACHS, Murice. A memória coletiva. São Paulo: Vértice, 1990.

MOURA, D.; et. al. A revitalização urbana: contributos para a definição de um conceito Operativo. Cidades-Comunidades e Territórios, n.12/13, p.15-34, dez. 2006. Disponível em:<http://revistas.rcaap.pt/cct/article/viewFile/9228/6675>. Acesso: 19/08/2018.

HOYLE, B. Development dynamics at the port-city interface. In HOYLE, B. S.; PINDER, D. A.; HUSAIN, M. S. (Eds.). Revitalising the Waterfront: International Dimension of Dockland Redevelopment. Chichester [etc.]: John Wiley \& Sons, 1994.

LEFEBVRE, Henri. O direito à cidade. São Paulo: Centauro, 1991.

SÀNCHEZ, Fernanda. A reinvenção das cidades para um mercado mundial. Chapecó, SC: Argos, 2010.

SERPA, Ângelo. O espaço público na cidade contemporânea. São Paulo: Editora Contexto, 2007.

TORRES, Luiz Henrique. Memórias do cais: o Porto Velho do Rio Grande. Rio Grande: Ed. da FURG, 2009.

VASQUES, Ramalho. As considerações de estudos de caso sobre brownfields: exemplos no Brasil e no mundo. Biblio $3 \mathrm{w}$, Revista Bibliográfica de Geografia y Ciências Sociales, Universidad de Barcelona, vol XI, n 648, 30 de abril de 2006. Disponível em: <www. ub. es/geocrit/ b3w - 648. htm>. Acesso: 22/08/2018. 
Recebido em 10 de setembro de 2018.

Aceito em 28 de outubro de 2018. 